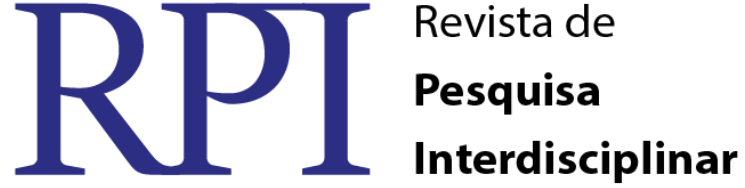

\section{AFETIVIDADE SOB O OLHAR DA TEORIA WALLONIANA: EXPERIÊNCIA COM A PESQUISA EPISTOLAR NO CURSO DE PEDAGOGIA}

\author{
Maria Thaís de Oliveira Batista-UFCG/CFP \\ Zildene Francisca Pereira - UFCG/CFP
}

\begin{abstract}
RESUMO
O presente trabalho teve como objetivo indagar o que estudantes de Pedagogia compreendem acerca do conceito de afetividade a partir do relato de experiências educativas agradáveis e desagradáveis vivenciadas ao longo da trajetória acadêmica no Curso de Pedagogia, bem como na formação básica como um todo. Participaram da pesquisa quatro (4) estudantes do Curso de Pedagogia, sendo que o local selecionado para a realização foi a Universidade Federal de Campina Grande, Campus de Cajazeiras/PB. A coleta dos dados foi realizada a partir da entrega de uma carta as estudantes, como forma de compreender o conceito destas acerca da afetividade a partir do relato de experiências educativas agradáveis e desagradáveis vivenciadas ao longo da trajetória acadêmica. Uma das participantes nos trouxe algumas experiências afetivas positivas para o seu desenvolvimento enquanto sujeito, e outras nos trouxeram vivências que as afetaram de forma negativa, ao ponto que em uma delas, deixaram até 'traumas' mediante algumas situações específicas ocorridas na sala de aula. Em relação à afetividade, vemos que esta é compreendida, como uma forma de afetar e ser afetado por sensações agradáveis e desagradáveis em meio as nossas vivências, porém, ela também foi compreendida, apenas, como uma forma que temos de afetar e de sermos afetados positivamente, sem levar em conta que ela perpassa uma discussão bem mais ampla, do que o senso comum compreende ser. Portanto, na medida em que os professores em formação, bem como os profissionais que já atuam no âmbito educacional, compreendem o desenvolvimento humano de forma não fragmentada, estes passam a enxergar a possibilidade de desenvolvimento integral do sujeito.
\end{abstract}

Palavras-chave: Afetividade, Teoria Walloniana, Formação de Professores.

\section{AFFECTIVITY UNDER A LOOK WALLONIAN THEORY: EXPERIENCE IN RESEARCH EPISTOLARY PEDAGOGY COURSE}

\begin{abstract}
This study aimed to investigate what Pedagogy students understand about the concept of affectivity from the report of pleasant and unpleasant experiences of education throughout the academic career in the School of Education, as well as basic training as a whole. The participants were four (4) students of the School of Education, and the site selected for the achievement was the Federal University of Campina Grande, Campus Cajazeiras / PB. Data collection was performed from the delivery of a letter the students as a way to understand the concept of these on the affection from the report of pleasant and unpleasant experiences of education throughout the academic career. One of the participants brought us some positive affective experiences for their development as a subject, and other brought us experiences that affected negatively, to the point that in one of them, left to "trauma" by some specific situations that occurred in the classroom. Regarding affectivity, we see that this is understood as a way of affecting and being affected by pleasant and unpleasant sensations through our experiences, however, it was also understood only as a way that we have to affect and be affected positively, without taking into account that it cuts across a much broader discussion than common
\end{abstract}


sense understands being. So in that teachers in training as well as professionals already working in the educational field, understand the human development not fragmented, they begin to see the possibility of full development of the subject.

Keywords: Affection, Wallonian Theory, Teacher Training.

\section{INTRODUÇÃO}

O presente trabalho é um recorte do terceiro eixo temático da análise dos dados da monografia intitulada "Conjuntos Funcionais na teoria Walloniana: o que estudantes do curso de Pedagogia compreendem acerca da relação afetividade e aprendizagem na universidade". Ao longo da discussão aqui proposta, tivemos o objetivo de indagar o que estudantes de Pedagogia compreendem acerca do conceito de afetividade a partir do relato de experiências educativas agradáveis e desagradáveis vivenciadas ao longo da trajetória acadêmica.

$\mathrm{Na}$ tentativa de alcançar o objetivo, previamente elaborado, que foi indagar o que estudantes de Pedagogia compreendem acerca do conceito de afetividade a partir do relato de experiências educativas agradáveis e desagradáveis vivenciadas ao longo da trajetória acadêmica, utilizamos para a composição da pesquisa, a escrita de uma carta, contendo uma contextualização do nosso interesse com a temática, bem como a proposta de que nos respondessem esta carta, como forma de suprir outros questionamentos que tínhamos mediante a pesquisa em estudo.

Este tipo de escrita que possibilita ao participante responder um questionamento através de uma carta, e lhe concebe uma maior liberdade no percurso que sua escrita pode tomar, é conhecido como epistolografia. O trabalho com o texto epistolar possibilita aos professores em formação, bem como aos professores formados e aos diversos pesquisadores, uma (re) valorização desse tipo de material, que necessita ganhar maior visibilidade e relevância dentro do universo de pesquisa (TAMAROZZI, 2007).

O trabalho foi realizado com a participação de quatro discentes do Curso de Pedagogia da Universidade Federal de Campina Grande, do Centro de Formação de Professores, Campus de Cajazeiras/PB. Toda a pesquisa girou em torno do estudo da teoria Walloniana no referido curso, e da necessidade de um trabalho mais significativo com essa temática nos diferentes cursos de formação de professores.

RPI Revista de Pesquisa Interdisciplinar, Cajazeiras, v. 1, Ed. Especial, 128 - 137, set/dez. de 2016. 


\section{Resultados e Discussão}

Em relação ao que compreende sobre afetividade, uma das participantes nos relata que se trata de uma "[...] maneira de você expor seus sentimentos, ou seja, é a forma pelo qual os indivíduos expressam seu carinho, dedicação, é o meio em que se estabelece uma relação entre os sujeitos [...]" (AÇUCENA). Ela nos trás a compreensão da afetividade como elemento primordial nas relações que são estabelecidas pelos sujeitos, ao ponto que nos relata que esta diz respeito aos momentos em que nos expressamos diante do outro.

Após relatar a sua compreensão sobre a afetividade, a discente nos traz experiências agradáveis e desagradáveis vivenciadas ao longo da educação básica, trazendo-nos dois relatos com duas professoras diferentes: um que considera agradável e que a teria influenciado de forma positiva no seu processo de aquisição do conhecimento e a outra que a teria afetado de forma negativa, na medida em que a fez se sentir inferior e desacreditada em relação ao desenvolvimento das suas potencialidades e assim nos especifica,

A primeira professora atuou de forma desagradável porque falava que eu tinha preguiça e não iria aprender e às vezes fazia me sentir inferior e excluída aos demais alunos, fazendo-me acreditar que nunca poderia aprender. Já a segunda agiu de forma contrária [...], pois incentivava e dizia que para se aprender é uma questão de tempo [...] (AÇUCENA).

Podemos analisar que Açucena demonstra desapontamento com a primeira professora do relato acima, pois esta não buscou estabelecer vínculos de cuidado, de confiança e de estímulos com a discente, na medida em que a todo o momento a inferiorizava com frases desestimulantes, o que a fazia se sentir excluída mediante as atividades realizadas em sala de aula.

Vemos a diferença do sentimento de Açucena, na medida em que discorre com alegria e entusiasmo, na sua carta, quando fala da segunda professora, ao ponto que ela nos relata a confiança e estímulo que esta professora lhe transmitia durante o seu processo de aquisição do conhecimento. Açucena considera que esta professora the afetou de forma agradável e, portanto, influenciou de forma positiva no seu desenvolvimento, ao fazê-la adquirir maior interesse diante da sua aprendizagem e uma significativa autoconfiança que a fez se tornar protagonista desse processo, pois

RPI Revista de Pesquisa Interdisciplinar, Cajazeiras, v. 1, Ed. Especial, 128 - 137, set/dez. de 2016. 
Quando se estabelecem relações de confiança na sala de aula, o aluno se sentirá mais à vontade para expressar suas reflexões, dúvidas, descobertas, participações e assim, construir seu processo de aquisição do conhecimento. Por outro lado, a relação problemática pode gerar sentimentos de insegurança, dúvida, medo e hostilidade com relação ao professor e aos colegas [...] (LIMA, 2000, p. 222).

O estímulo, a confiança e a dedicação na educação de crianças são instrumentos primordiais para os objetivos que se desejam alcançar, pois, é através desses aspectos vivenciados na interação que a criança se sentirá sujeito importante e responsável pela sua aprendizagem, na medida em que compreende que está sendo acompanhada por um profissional que se preocupa com o desenvolvimento das suas potencialidades.

No que diz respeito a temática central da nossa pesquisa, a segunda participante diz que a afetividade

[...] é algo sigiloso e íntimo que o ser humano tem em conhecer o outro, saber o que o outro sente ou não em determinados momentos de suas vidas, sejam bons ou ruins, alegrias e tristezas, seja por meio do diálogo, ou até mesmo ao sentir compaixão dos sentimentos das pessoas [...] (AMARÍLIS).

Amarílis nos trás um entendimento de afetividade que diz respeito às relações que estabelecemos com o nosso meio, na medida em que compreende que esta seja a necessidade de nos colocarmos no lugar do outro, como uma forma de empatia com os nossos pares, e se tratando do professor, este precisa estar atento a todas as formas de expressão dos seus educandos, tanto aos estados de bem-estar quanto de mal-estar destes, pois, é a partir dessas expressões que conseguiremos compreendê-los para além do seu desenvolvimento cognitivo. Amarílis nos mostra um entendimento, mesmo que inicial, do que seja a afetividade, quando nos aponta que ela se refere ao fato de você compreender o que o outro sente, seja este sentimento bom ou ruim, que é justamente o que Wallon (1941/2007) nos faz entender, essa afetividade que abarca os estados agradáveis vividos pelos sujeitos, mas também, as suas vivências desagradáveis, tudo está relacionado ao nosso estar no mundo sendo afetados e afetando as relações. 
Ao nos trazer algumas vivências afetivas agradáveis e desagradáveis, a discente recorda de duas professoras: uma do $4^{\circ}$ e a outra do $5^{\circ}$ ano que lhe afetaram de forma negativa e positiva respectivamente. Assim diz que

As recordações de minha professora do $4^{\circ}$ ano não são as melhores, pois, tinha dias que ficava apreensiva em falar com ela, a mesma tem um temperamento forte e o seu mau humor contaminava a todos, as aulas eram horríveis [...]. A minha educadora do $5^{\circ}$ ano que foi fundamental para mim, me apoiando nos momentos difíceis [...] gostava de conversar com ela me sentia segura [...] (AMARÍLIS).

Em relação à primeira professora que lhe ensinou no $4^{\circ}$ ano do Ensino Fundamental, Amarílis nos relata que não tem boas recordações, pois esta nunca buscou estabelecer uma relação mais próxima com os seus educandos, sendo vista, na maioria das vezes, como mal humorada e causando medo nas crianças. Essa realidade vivida em sala de aula é um aspecto que merece atenção especial por parte dos professores, na medida em que o medo limita o processo de desenvolvimento das crianças e isso está presente nas salas de aula de Educação Infantil e Anos Iniciais do Ensino Fundamental, especificamente, mas podemos citar, também, que na própria Universidade esse medo acompanha os discentes de modo que desfavorece o processo de ensino-aprendizagem entre adultos.

O medo pode ser verificado em situações novas ou parcialmente novas para as crianças. A criança pode sentir medo numa simples mistura de coisas ou situações que lhe sejam familiares ou desconhecidas. O medo na criança pode ser provocado, por exemplo, pela mescla do objeto conhecido com uma situação completamente estranha para ela (ALMEIDA, 2005, p.97).

O contato constante com o medo na sala de aula pode limitar o desenvolvimento das potencialidades do educando, na medida em que este experiência, cotidianamente, novas vivências, que lhe são estranhas e necessitam ser trabalhadas com um olhar atento e cuidadoso por parte do professor, pois é a partir de situações cada vez mais frequentes de desconforto e medo no ambiente escolar, que a criança se distanciará consequentemente dos resultados que se esperam no seu processo de aprendizagem.

Já em relação a sua professora do $5^{\circ}$ ano do Ensino Fundamental, Amarílis nos relata que esta foi de grande valia para a pessoa que ela se tornou hoje, pois a professora sempre RPI Revista de Pesquisa Interdisciplinar, Cajazeiras, v. 1, Ed. Especial, 128 - 137, set/dez. de 2016. 
buscou nas suas aulas possibilitar um diálogo aberto entre professor-aluno, ao ponto que demonstrava confiança e dedicação nas atividades que eram realizadas no dia-a-dia da sala de aula. Em relação a isso Gadotti (1991, p. 69) diz que "[...] o diálogo é uma exigência que possibilita a comunicação" e "para pôr em prática o diálogo, o educador deve colocar-se na posição humilde de quem não sabe tudo".

A nossa terceira participante nos relata sobre o seu entendimento acerca do que seja afetividade, que segundo ela: “[...] é toda ação que possa atingir o outro, a afetividade vai bem mais além que a relação de carinho afetivo, mas sim se trata de atitudes que provoquem o sujeito seja de forma positiva ou negativa [...] (HORTÊNSIA).

Hortênsia nos relata que a afetividade é uma forma de afetar o outro de forma negativa ou positiva nas diversas vivências dos sujeitos, pois em se tratando de relações é necessário que compreendamos que como relata Antunes (2003, p. 9) “[...] cada pessoa é, e sempre será um verdadeiro universo de individualidade; suas ações, seus motivos, seus sentimentos constituem paradigma único" e, portanto, necessitam ser acompanhados por profissionais que os compreendam na sua integração.

De acordo com Hortênsia a afetividade não se trata, apenas, dos gestos de carinho e afeto, pois, ela perpassa, também, as marcas negativas que os sujeitos podem deixar na vida de outrem, por meio de atitudes que despertam a desmotivação, o medo ou qualquer outro tipo de sentimento que limita o desenvolvimento dos sujeitos. Ainda em relação a isso ela nos relata que "[...] mesmo que seja através de uma atitude que possa parecer rígida, o professor pode estar instigando a criança [...] de maneira positiva, contribuindo assim para a formação do educando" (Hortênsia). O professor em meio a essa realidade

[...] precisa conhecer e ouvir a criança. Deve conhecê-la não apenas na sua estrutura biofisiológica e psicossocial, mas também na sua interioridade afetiva, na sua necessidade de criatura que chora, ri, dorme, sofre e busca constantemente compreender o mundo que a cerca, bem como o que ela faz ali na escola (SALTINI, 2008, p.63).

A autora enfatiza o que viemos apontando até aqui, que é a necessidade do professor estabelecer, juntamente ao trabalho que é desenvolvido em sala de aula, relações agradáveis com os seus educandos, para obter um bom resultado no que se deseja alcançar, pois a formação de todo e qualquer sujeito está imersa em necessidades particulares, desejos, emoções, sentimentos, que precisam ser vistos e trabalhados pelos profissionais da educação e 
isso só será possível, através do conhecimento desses profissionais acerca das singularidades que compõe o desenvolvimento de cada sujeito.

Em relação ao entendimento do conceito de afetividade, a última participante da nossa pesquisa nos relata que

[...] a afetividade está relacionada a afetar alguém, seja positivamente ou negativamente. Tendo em vista a prática docente, esse é um fator muito importante, pois pode tanto impulsionar o desenvolvimento da aprendizagem da criança ou pode, puro e simplesmente, gerar um bloqueio no seu desenvolvimento (GARDÊNIA).

Vemos que Gardênia também tem o mesmo entendimento das discentes analisadas anteriormente acerca do conceito de afetividade, quando esta nos diz que refere-se ao ato de afetar de forma negativa ou positiva as pessoas que convivemos. E nos relata, também, sobre as marcas que essas vivências afetivas, sejam elas agradáveis ou não, podem deixar ao longo da nossa formação acadêmica/humana. Essas vivências podem deixar tanto marcas de superação, de alcance do que se é almejado, quanto marcas de desestímulo, de medo, como a própria discente nos relata, marcas que acabam ocasionando certo bloqueio diante do desenvolvimento dos sujeitos. Notamos isso claramente quando ela nos relata uma experiência afetiva desagradável vivenciada durante a graduação em Pedagogia e diz

Eu estava passando por um momento delicado na família, mas isso pouco importou à professora. Meu desempenho no trabalho de dramatização exigido por ela não foi tão bom, admito, mas isso não lhe dava o direito de me humilhar diante dos demais colegas de sala. Até hoje não superei esse "trauma" (GARDÊNIA).

Está explícito, no depoimento de Gardênia, o bloqueio emocional que ela carrega consigo no que se refere ao trabalho com dramatização e isto se deve a forma como a professora se posicionou mediante o estado da discente nesse dia. Vemos a realidade de que esse tipo de situação, não acontece, apenas, na educação básica, mas sim em qualquer nível de ensino, em qualquer local que estejamos lidando com pessoas, que necessitam serem compreendidas na sua integração, no que se refere aos aspectos emocionais, aos seus sentimentos mediante tantas situações que se fazem presentes no nosso dia-a-dia. 
Vemos então, nessa experiência vivenciada por Gardênia a falta de importância que foi dada por esta professora, ao contexto que envolve o desenvolvimento da aluna, ao ponto que não buscou se sensibilizar para com as limitações desta mediante a atividade proposta em um determinado dia de aula. Esse modelo de professor/a ultrapassa o nível de ensino, pois existem desde a pré-escola até o ensino superior. Podemos enfatizar que

O professor autoritário, o professor silencioso, o professor competente, sério, o professor incompetente, irresponsável, o professor amoroso da vida e das gentes, o professor mal-amado, sempre com raiva do mundo e das pessoas, frio, burocrático, racionalista, nenhum deles passa pelos alunos sem deixar sua marca (FREIRE, 1996, p. 73).

Ao final da análise das cartas escritas pelas participantes da pesquisa, reforçamos o nosso entendimento de que a afetividade perpassa uma série de aspectos que vão desde a vivência com sensações agradáveis, quanto desagradáveis durante a nossa trajetória de vida estudantil/profissional/pessoal. E nesse ínterim, as vivências que são experenciadas ao longo desse processo, deixarão marcas para toda a vida do sujeito, sejam elas positivas ou negativas, e sabendo disso, o professor necessita estar atento as marcas que almeja deixar na formação dos seus educandos e isto se inicia quando este reflete acerca de que sujeito deseja formar em meio a atual sociedade em que vivemos.

Sabemos, ainda, que estudar a temática da afetividade não é uma tarefa simples, mas que também não é impossível desde que tenhamos clareza da intencionalidade do trabalho que envolve a docência, a relação professor-aluno em sala de aula a partir das diferentes capacidades. A participação das quatro discentes do Curso de Pedagogia vem nos alertar para a necessidade de compreendermos o que é essa afetividade que utilizamos na fala diariamente e que nem sempre entendemos seu real sentido.

É imprescindível levarmos em consideração que estamos no Curso de Pedagogia para aprendermos a lidar com a docência em salas específicas da Educação Infantil e Anos Iniciais, mas se não obtivermos noções básicas do comprometimento com a criança integral como nos diz Wallon (1941/2007), a partir das diferentes teorias, será difícil concretizarmos um trabalho completo que envolva a criança em suas várias dimensões, pois nós, enquanto pedagogas, não fomos formadas para tal especificidade.

RPI Revista de Pesquisa Interdisciplinar, Cajazeiras, v. 1, Ed. Especial, 128 - 137, set/dez. de 2016. 


\section{Conclusão}

O trabalho com as cartas como um instrumento de coleta de dados para a nossa pesquisa, nos possibilitou uma experiência ímpar com os sujeitos e o nosso objeto de estudo, pois, pudemos a partir destas, ter uma visão mais particular das singularidades de cada participante da pesquisa, bem como sobre os seus entendimentos acerca do conjunto funcional da afetividade, considerado primordial no desenvolvimento do sujeito. Esta técnica da epistolografia acarretou em dados significativos para os objetivos que elaboramos para essa pesquisa, na medida em que as discentes puderam nos expressar por meio dessa escrita, vivências afetivas desde a educação básica, como forma de compreendermos o entendimento de tal acerca do que seja afetividade.

Uma das participantes nos trouxe algumas experiências afetivas positivas para o seu desenvolvimento enquanto sujeito, e outras nos trouxeram, também, vivências que as afetaram de forma negativa, ao ponto que em uma delas, deixaram até "traumas" mediante algumas situações específicas ocorridas na sala de aula. Diante disso, compreendemos que realmente a afetividade "[...] refere-se à capacidade, à disposição do ser humano de ser afetado pelo mundo externo/interno por sensações ligadas a tonalidades agradáveis ou desagradáveis" (ALMEIDA; MAHONEY, 2007, p.19).

Em relação à afetividade, vemos que esta é compreendida, como uma forma de afetar e ser afetado por sensações agradáveis e desagradáveis em meio as nossas vivências, porém, ela também foi compreendida, apenas, como uma forma que temos de afetar e de sermos afetados positivamente, sem levar em conta que ela perpassa uma discussão bem mais ampla, do que o senso comum compreende ser.

\section{REFERÊNCIAS}

ALMEIDA, L; MAHONEY, A. A dimensão afetiva e o processo de ensino-aprendizagem. In: ALMEIDA, L; MAHONEY, A. (Orgs.). Afetividade e aprendizagem: contribuições de Henri Wallon. São Paulo: Loyola, 2007.

ALMEIDA, A. R. S. A emoção na sala de aula. 2. ed. Campinas, SP: Papirus, 2005.

ANTUNES, C. Relações Interpessoais e Auto-estima. Petrópolis, RJ: Vozes, 2003.

FREIRE, P. Pedagogia da Autonomia: saberes necessários à prática educativa. São Paulo: Paz e Terra, 1996.

RPI Revista de Pesquisa Interdisciplinar, Cajazeiras, v. 1, Ed. Especial, 128 - 137, set/dez. de 2016. 
GADOTTI, M. Convite à leitura de Paulo Freire. São Paulo: Scipione, 1991.

LIMA, M. do S. M. O problema da indisciplina nas classes de $1^{\text {a }}$ a $4^{\text {a }}$ séries do Ensino Fundamental. 257 f. Dissertação (Mestrado). Universidade de Brasília, Instituto de Psicologia, Brasília, 2000.

OLIVEIRA, M. Como fazer pesquisa qualitativa. 2 ed.- Petrópolis, RJ: Vozes, 2008.

SALTINI, C. J. P. Afetividade e inteligência. Rio de Janeiro: Wak, 2008.

TAMAROZZI, E. Cartas de Moçambique: uma experiência de afetividade no processo de formação de professores. In: ALMEIDA, L. R. de.; MAHONEY, A. A. (Orgs.). Afetividade e aprendizagem: contribuições de Henri Wallon. São Paulo:Loyola, 2007.

WALLON, H. Psicologia e Educação da Infância. Lisboa: Estampa, 1973.

WALLON, H. A evolução psicológica da criança. Tradução: Claudia Berliner. São Paulo: Martins Fontes, 1941/2007. 